\title{
Mood-congruent and mood-incongruent learning
}

\author{
MIKE RINCK and ULRICH GLOWALLA \\ Justus-Liebig-University Giessen, Giessen, Germany \\ and \\ KLAUS SCHNEIDER \\ University of Bochum, Bochum, Germany
}

\begin{abstract}
We report two experiments that investigate the effect of an induced mood on the incidental learning of emotionally toned words. Subjects were put in a happy or sad mood by means of a suggestion technique and rated the emotional valence of a list of words. Later on, they were asked to recall the words in a neutral mood. For words with a strong emotional valence, mood-congruent learning was observed: strongly unpleasant words were recalled better by sad subjects and strongly pleasant words were recalled better by happy subjects. The reverse was true for slightly toned words: here, mood-incongruent learning was observed. Both effects are predicted by a twocomponent processing model that specifies the effect of the mood on the cognitive processes during learning. Further evidence for the model is given by rating times measured in Experiment 2.
\end{abstract}

During the last decade, numerous studies have demonstrated the influence of mood states on the recall of verbal material (for reviews, see Blaney, 1986; Bower, 1981; Guenther, 1988). Mainly, three phenomena have been investigated by "mood and memory" researchers: mooddependent retrieval, mood-congruent recall, and moodcongruent learning. The effects of mood states on memory have been intensively investigated because of their importance for understanding the relationship between emotional and cognitive processes. This is true in normal subjects as well as in patients suffering from emotional disorders such as depression (e.g., Bower, 1981; Bower \& Cohen, 1982; Bower, Gilligan, \& Monteiro, 1981; Clark \& Teasdale, 1982; Derry \& Kuiper, 1981; Eich \& Metcalfe, 1989; Fiedler \& Ströhm, 1986; Snyder \& White, 1982; Teasdale \& Russell, 1983; Weingartner, Miller, \& Murphy, 1977). The experiments reported here investigated mood-congruent learning (i.e., the improved learning of material whose emotional valence matches the learning mood). Mood-congruent learning appears to be a stable phenomenon, though some failures to replicate it have been reported (Kelley, 1982; Mecklenbräuker \& Hager, 1984).

The research reported here was supported in part by the Deparment of Psychology, University of Marburg, and by Grant G1 123/1-2 from the German Research Foundation (DFG) to Ulrich Glowalla. This support is gratefully acknowledged. We sincerely thank Gordon Bower, Eric Eich, Klaus Fiedler, R. Kim Guenther, and an anonymous reviewer for helpful comments on earlier versions of this paper. We also thank Sascha Engelbrecht, Joachim Hasebrook, and Bettina Lovenberg for their help in conducting Experiment 2, as well as Eni Becker and Evelin Ford for their help in preparing the paper. Correspondence conceming this article should be sent to Mike Rinck, Department of Psychology. University of Giessen, Otto-Behaghel-Str. 10/F, 6300 Giessen, Germany.
The dominant theoretical framework for the explanation of mood effects on memory is network theory, as proposed by Bower (1981) and Bower and Cohen (1982). In this framework, emotions are conceptualized as nodes in a semantic network, much like other nodes that symbolize concepts. Emotion nodes can be activated by physiological or verbal means (e.g., by mood inductions). An activated emotion node not only produces the pattern of automatic arousal and expressive behavior related to that emotion, it also spreads activation to connected nodes in the memory network, thereby activating concepts and memories that are congruent with the activated emotion. Mood-congruent learning can be explained in this framework by assuming that emotionally toned material activates congruent emotion nodes and inhibits incongruent nodes. Thus, mood-congruent material intensifies the prevailing mood and incongruent material weakens it.

On the basis of this account, one explanation offered for mood-congruent leaming reads that leaming in a state of intensified mood is more effective because this renders the to-be-learned material more distinctive and less prone to interference. An alternative explanation is based on mood-preserving behavior: to maintain their mood, people focus on mood-congruent information and elaborate it more than incongruent information, which would weaken the mood. In the context of laboratory experiments such as the ones reported here, the latter explanation seems more plausible to us. First, the mood we induced is presumably not as intensive as the feelings one experiences during a happy or sad life event. So we suspect that the level of mood intensity achieved is not sufficient for the first explanation to apply. Furthermore, there is some evidence that intensive moods facilitate learning predominantly if subjects see the presented material as 
the cause of their mood (Bower, 1987). However, this was not the case in our experiments. Moreover, subjects are usually instructed to maintain the induced mood, and elaborating mood-congruent material is an effective and easy way to achieve this. As far as we know, there is no empirical evidence to decide if none, one, or both of the proposed explanations are correct (see also Bower, 1987). Fortunately, this is not crucial for our argument, because the interpretation of our results does not depend on how the observed mood-congruence effects are explained. The focus of our argument is on the existence and explanation of mood-incongruent learning, and the experiments were not designed to differentiate between alternative explanations of mood-congruent learning.

A central prediction of the network view is that mood leads directly to mood-congruence effects. Therefore, an experimental finding that is hard to explain by a simple network model is mood-incongruent learning (Clark, Teasdale, Broadbent, \& Martin, 1983; Fiedler, Pampe, \& Scherf, 1986). Subjects in Clark et al.'s (1983) experiment performed a lexical decision task while they were in an induced happy or sad mood. The material of the lexical decision task consisted of nonwords as well as positive, neutral, and negative personality-trait words. After the lexical decision task, the subjects received a surprise free-recall test: they were asked to recall the words of the lexical decision task. Though the induced mood had no effect on the lexical decision times, it produced moodincongruent learning of the words. Happy subjects recalled more negative words than positive words; sad subjects recalled more positive words than negative words. Fiedler et al. (1986) induced a happy or neutral mood in their subjects using Velten's (1968) procedure. The material to be learned consisted of 36 sentences describing an individual's behavior with regard to six categories of social behavior. Each sentence described one behavior, and each category comprised six of these behavioral descriptions. An example of a positive behavior belonging to the "sociability" category is, "With his jokes, he was the life of the party." Three of the categories were predominantly positive (i.e., five of the six sentences of this category described socially positive behavior). The other three categories were predominantly negative (i.e., five of the six sentences described negative behavior). After learning the behavioral descriptions, subjects were asked to recall as many descriptions as possible. A category was rated as recalled if at least one description belonging to that category was remembered. The authors obtained no effect of mood on learning of single descriptions. However, they found mood-incongruent learning of categories: happy subjects recalled more negative categories than positive categories, whereas subjects in a neutral mood recalled about the same proportion of positive and negative categories.

In both the Clark et al. (1983) study and the Fiedler et al. (1986) study, the finding of an incongruence effect was unexpected. What is even more important, this effect cannot be explained on the basis of a simple network model of emotion because this model predicts better learning of mood-congruent items in general. As we have seen, however, this is clearly not the case: mood-congruent learning as well as mood-incongruent learning and null findings were observed. Nevertheless, we believe that it is not necessary to abandon the network framework in order to incorporate these conflicting results. Instead, we propose to extend the original network model by maintaining the representational assumptions and developing more detailed processing assumptions. We shall argue that the extended model can explain both mood-congruent and mood-incongruent learning. Therefore, the remainder of this paper describes two experiments that were specifically designed to demonstrate cases of both moodcongruent and mood-incongruent learning within the same experimental setting.

The basic procedure was identical in both experiments. First, subjects were put in a happy or sad mood by use of a suggestion technique. Next, they rated the emotional valence of several words on a rating scale ranging from -3 for very unpleasant to +3 for very pleasant. The word list contained the whole range of strongly pleasant, slightly pleasant, slightly unpleasant, and strongly unpleasant words: examples of these four categories are "to kiss," "bird," "wetness," and "to kill," respectively. Each word was presented for a fixed amount of time. After the rating task, subjects were put back in a neutral mood. Later on, they received a surprise free-recall test (i.e., they were asked to recall as many of the rated words as possible). The question of interest was how many words from each of the four categories were recalled by subjects who had been happy or sad during learning.

Why should one expect both mood-congruent and mood-incongruent learning using this paradigm? To answer this question, we have to consider the effect of the mood on the valence ratings and the cognitive processes during the learning task. It was often demonstrated that induced or natural mood states affect judgments of ambiguous stimuli-for example, personal experiences, pictures from the Thematic Apperception Test, interpersonal behaviors, personal capabilities, or consumer goods (Bower, 1981; Forgas, Bower, \& Krantz, 1984; Isen, Shalker, Clark, \& Karp, 1978; Kavanagh \& Bower, 1985; Roth \& Rehm, 1980). Happy subjects usually give more positive judgments and interpretations of ambiguous stimuli than do sad or angry subjects. Therefore, we suppose that the valence impressions and ratings of the words in the rating task will be influenced by the subjects' mood as well: happy subjects will perceive and rate the words as more pleasant than will sad subjects.

The expected rating bias is shown in Figure 1: the ratings of mood-incongruent words (like "wetness" or "to kill" in the case of a happy subject) will be biased toward the neutral zero point of the rating scale. The ratings of mood-congruent words (like "to kiss" or "bird" in the case of a happy subject), on the other hand, will be shifted away from the zero point toward the mood-congruent end of the rating scale. The bias is probably weaker for 


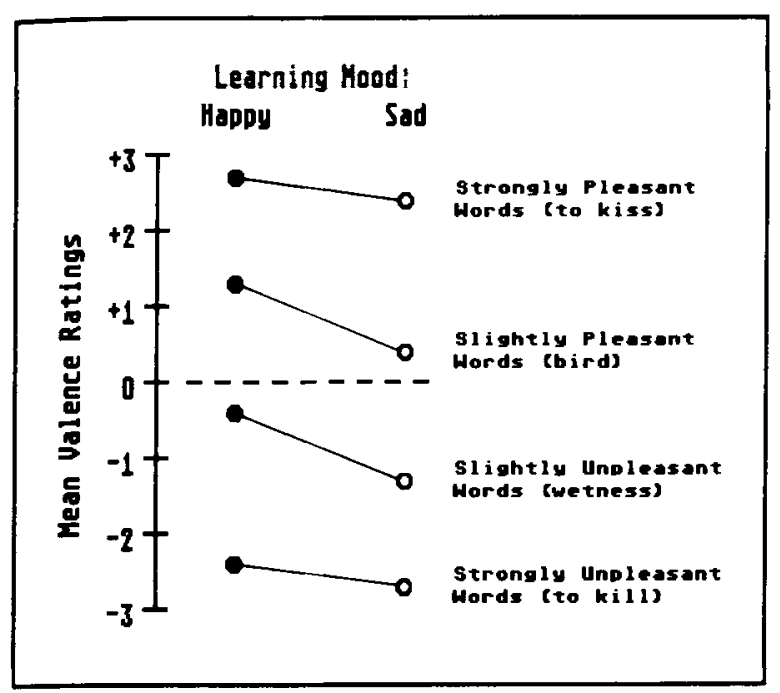

Figure 1. Predicted valence ratings of the four word categories given by happy and sad subjects according to our two-component processing model.

strongly toned words due to floor and ceiling effects, but this more specific assumption is not central to our general argument. The existence of the rating bias is one of the hypotheses tested in this study. Moreover, it is a precondition for mood-incongruent learning to occur in our experiments, as we shall explain below.

The process assumptions of the model distinguish between two different cognitive processes involved in the rating task. Of course, there may be more than two processes involved in rating the emotional valence of a word. Nevertheless, we will restrict our discussion to those two processes that are relevant to our argument. The first process is called valence determination, which denotes the determination of the emotional valence of a word that is necessary to give a valence rating of the word. Subjects rate the valence of a given word by determining the valence of the associated feelings, memories, and fantasies activated by the word. The ease of valence determination depends on the strength of the emotional tone of the word: strongly toned words are classified easily because they quickly activate many associations of the same valence. On the other hand, slightly toned words are more difficult to classify because they activate conflicting associations that vary in emotional valence. This is illustrated in Figure 1: the greater the distance between the valence of a word and the zero point of the scale, the easier it should be to determine its valence.

The second process is called additional elaboration, which refers to associative connections between the presented word and other concepts of the same valence. Subjects produce these additional elaborations after they have given their rating response and before the next word is presented. This was possible in our study because each word was presented for a fixed amount of time, which was considerably longer than the average rating time. In accordance with the original network model, we assume that the amount of additional elaboration depends on the congruence between mood and word valence: subjects elaborate more on congruent words than on incongruent ones in order to maintain the induced mood. This is also illustrated in Figure 1: the closer the valence of the word is to the congruent end of the scale, the more it will be elaborated.

The distinction between valence determination and additional elaboration is meant to imply that they are different aspects of the subject's cognitive processing before and after the rating response to a given word. The distinction is important because we shall argue that differences in the ease of valence determination produce moodincongruent learning of slightly toned words, whereas differences in the amount of additional elaboration after the valence rating result in mood-congruent learning of strongly toned words. The rationale of our reasoning will become more apparent, if we look at the four different categories of words separately.

The emotional valence of strongly mood-congruent words such as to kiss for a happy subject or to kill for a sad one is obvious, and the rating bias makes it even more evident, so the valence determination should be easy. Because of their clear and mood-congruent valence, these words are well suited for maintaining the induced mood. Therefore, subjects will elaborate on these words and thereby encode them efficiently in memory while they are waiting for the next word to be presented.

The valence determination for strongly mood-incongruent words such as to kill for a happy subject or to kiss for a sad one is also easy, despite the fact that their valence impressions are biased toward the neutral point. This is true because of the unequivocal valence of these words: the bias is not strong enough to render the valence of these words equivocal. So, even for a happy subject, words such as to kill remain clearly unpleasant. Therefore, the valence of strongly mood-incongruent words should be determined as easily as the valence of strongly mood-congruent words. However, the amount of additional elaboration should differ: strongly incongruent words weaken the induced mood. Therefore, subjects will avoid elaborating these words after they have rated their valence. Thus, these words are not as efficiently encoded in memory as strongly mood-congruent words.

The valence of slightly mood-congruent words such as bird for a happy subject or wetness for a sad one is not as obvious as the valence of strongly toned words. However, the valence determination is facilitated by the rating bias because the valence impressions are shifted away from an emotionally neutral impression (see Figure 1). A word such as bird, for example, might usually possess only a very slight emotional tone for a given subject, but the induction of a happy mood makes the word seem clearly pleasant. Thus, the valence rating of slightly mood-congruent words becomes easier as a result of the mood induction. With regard to additional elaboration, the rating bias should lead to more congruent associations, 
but this effect is probably not strong enough to reduce the relative proportion of incongruent associations substantially. Therefore, slightly mood-congruent words should activate mood-congruent associations as well as mood-incongruent and neutral associations. This makes them less useful for maintaining the induced mood, so subjects will not elaborate these words very much.

The emotional valence of slightly mood-incongruent words such as wetness for a happy subject or bird for a sad one is also not unequivocal, and the determination of their valence is rendered even more difficult by the mood induction. This is true because the valence impressions of these words are shifted toward a neutral impression, resulting in a more difficult valence determination (see Figure 1). A word such as wetness, for example, might usually be regarded as slightly unpleasant by a given subject, because it is usually connected to unpleasant experiences, such as "getting wet in the rain." However, the induction of a happy mood primes positive associations, so that wetness might also activate pleasant associations, such as "taking a bath on a hot day." These conflicting associations render the subject's rating task more difficult. Therefore, subjects have to invest more cognitive effort to determine the valence of these words, relative to slightly mood-congruent words. Considering the amount of additional elaboration, these words are very similar to slightly mood-congruent words. They also activate mood-congruent, mood-incongruent, and neutral associations, so subjects will not elaborate them very much.

According to this model, the cognitive processing of strongly mood-congruent and mood-incongruent words differs substantially only with regard to the amount of additional elaboration after the valence rating. Furthermore, this difference predicts mood-congruent learning of strongly toned words. On the other hand, the processing of slightly mood-congruent and mood-incongruent words differs substantially only with regard to the ease of valence determination, predicting mood-incongruent learning of slightly toned words. The first prediction is identical to the one made by the original network model; the second one is derived from our two-component processing model. One of the component processes-namely, additional elaboration-can already be used in the original model in order to explain mood-congruent learning. The other process-namely, valence determinationconstitutes the new feature of the extended model. It serves to explain mood-incongruent learning. With regard to the representational assumptions, our model is equivalent to the original network model, as proposed by Bower (1981) and Bower and Cohen (1982).

Hence, according to our model, there are three important factors involved in determining the kind of mooddependent learning that will be observed: the subject's mood during learning (happy or sad), the direction of the emotional valence of the materials (pleasant or unpleasant), and the strength of the emotional valence of the materials (slight or strong). These three factors were varied sys- tematically in Experiment 1 in order to test our predictions regarding the rating bias, mood-congruent learning of strongly toned words, and mood-incongruent learning of slightly toned words. The main objective of Experiment 1 was to demonstrate the predicted effects-specifically, mood-incongruent learning of slightly toned words.

\section{EXPERIMENT 1}

\section{Method}

Design. The combination of the three independent variableslearning mood (happy or sad), word valence (pleasant or unpleasant), and valence intensity (slightly or strongly toned)-yielded a $2 \times$ $2 \times 2$ design. Learning mood was varied as a between-subjects factor, with half of the subjects receiving the happy mood induction and the other half receiving the sad mood induction. Word valence and valence intensity were varied as within-subjects factors (i.e., every subject learned strongly unpleasant, slightly unpleasant, slightly pleasant, and strongly pleasant words during the rating task of the experiment). The dependent variables of interest were the valence rating and recall of each word.

Subjects. Fifty-nine undergraduates of the Philipps-University Marburg participated as subjects in the experiment, which was announced to investigate "the relation of mood and word impression." They received either course credit or payment for their participation. Eleven subjects were excluded from the analyses for reasons described below. Half of the remaining 48 subjects had received the happy mood induction; the other half had received the sad mood induction. The subjects were randomly assigned to the two mood inductions.

Materials. A list of 24 nouns and adjectives containing 12 pleasant and 12 unpleasant words was constructed. These words were selected from a list of 50 words, whose emotional valence had been rated in a pretest by a different set of 36 undergraduates in a neutral mood. Both categories of selected pleasant and unpleasant words contained both slightly and strongly toned words, as rated by the pretest subjects. English translations of the pleasant German words in order of increasing pleasantness ratings in the pretest were courageous, splendid, strong, shiny, smart, celebration, landscape, gift, funny, garden, humor, and meadow. English translations of the unpleasant words in order of increasing unpleasantness were snake, cellar, angry, dirty, broken, bloody, cries, lonely, worry, guilty, poverty, and illness. Both word categories had comparable mean values of concreteness, imagery, meaningfulness, and frequency, as determined by the word lists published by Baschek, Bredenkamp, Oehrle, and Wippich (1977) and Wippich and Bredenkamp (1979). Word length was controlled by using only twosyllable words. Another six words were used as practice words at the beginning of the rating task. None of the $\mathbf{3 0}$ words appeared in the instructions or in the mood inductions. We used only 30 words to keep the duration of the rating task below $10 \mathrm{~min}$. This seemed necessary because prior tests had shown that the effect of the mood induction tended to decrease after this time.

Procedure. Each subject was tested individually on 2 consecutive days. The first day began with the mood induction: The subject was seated in a relaxation chair and received instructions, after which the experimenter left the room. Next, the tape-recorded mood induction was played to the subject at a comfortable volume. The mood induction consisted of a suggestion technique developed by Fydrich and Lambert (e.g., Lambert, 1985). The first part of the induction was identical for both moods. It was a relaxation instruction using progressive muscle relaxation. The first part served to put the subjects in a relaxed state of higher susceptibility. It was immediately followed by the second part. This part was the acrual 
mood suggestion, which differed between mood groups. The happy mood suggestion started with the symbols of intensifying light and strength. Then, feelings of expectation, joy, mental balance, optimism, self-confidence, safety, activity, and warmth were suggested in increasing intensity. The sad mood induction, on the other hand, started with the symbol of spreading darkness. Afterwards, feelings of depression, fear, discontent, lack of joy, helplessness, pessimism, passivity, and resignation were suggested in increasing in tensity. Pretests had shown that this technique is effective enough to induce a happy or sad mood of considerable strength and realistic quality. On the other hand, it is ethically justifiable because it does not work against the subjects' free will. The subjects were instructed to feel the suggested mood as intensively as possible, but they were free to interrupt the suggestion if the mood became too intense for them. The whole mood induction took about $25 \mathrm{~min}$.

The mood induction was directly followed by the rating task. Each word was rated in the following way. Using a slide projector, the word was presented on a screen in front of the subject for $6 \mathrm{sec}$. Then, the rating scale was presented on the screen for another 6 sec. The scale ranged from -3 (very unpleasant) via 0 (neutral) to +3 (very pleasant). The subjects were instructed not to rate the valence of the word before the presentation of the rating scale and to use only whole numbers between -3 and +3 . The ratings were given orally and were tape-recorded for later transcription. Every subject rated 30 words altogether (i.e., 6 practice words followed by the 24 experimental words). This took 8 min to be completed. Practice words were excluded from the analyses. The difference between practice words and experimental words was not obvious to the subjects. The presentation order of the 24 experimental words was varied systematically following a Latin square to control for possible order effects.

Immediately after the end of the rating task, we controlied the effect of the mood induction. The subjects rated their mood by indicating on a 7-point scale how well the following three statements described their mood: "I am in a cheerful mood right now," "I am in a balanced mood right now," and "I am in a depressed mood right now." Furthermore, the subjects were questioned by the experimenter about strength and duration of the effect of the mood induction. The subjects who indicated an insufficient effect (e.g., by rating the first statement as a better description of their mood than the last statement after having received the sad mood induction) were excluded from the analyses. This was true for 10 subjects. Among the remaining subjects, the happy subjects rated the first statement as a better description of their mood than did sad subjects, and the reverse was true for the third statement. The manipulation check was followed by the presentation of a second tape-recorded relaxation suggestion. This suggestion served to put all subjects back into a neutral mood at the end of the first day of the experiment. An experimental session on the first day lasted for about $50 \mathrm{~min}$.

The following day, the subjects returned to the experimental room expecting to rate another set of words without a preceding mood induction. Instead, they were given a surprise free-recall test. They were asked to recall the words they had rated the day before. The recall test was limited to $5 \mathrm{~min}$, and the answers were tape-recorded. Only 1 of the subjects had expected a recall test, and the data of this subject were excluded from the analyses because she had memorized the words during the rating task.

\section{Results and Discussion}

Valence ratings. As expected, the happy subjects rated the 24 experimental words as more pleasant than the sad subjects did. The rating bias was in the predicted direction: the mean rating given by the happy subjects was +0.25 and the mean rating given by sad subjects was -0.37 . This difference is statistically reliable $[F(1,46)=$
24.07, $p<.01$ ]. It should be mentioned that the cause of this rating bias is not perfectly clear. The possibility of a demand effect cannot be ruled out because the subjects might have had the hypothesis that we expected this rating bias. However, in this case, the relevant point is not the cause of the rating bias but its existence, because, according to our model, it is the precondition for moodincongruent learning to occur in the experiment.

To analyze the valence ratings in more detail, we checked whether the rating bias appeared within all four categories of words (slightly and strongly pleasant, slightly and strongly unpleasant). This analysis was complicated by the fact that the classification of words into the categories had to be done individually for each subject. Although the rank order of mean ratings of all 48 subjects taken together matched the rank order of mean ratings determined by the pretest very well $(R=.96, p<.01)$, many subjects' ratings deviated strongly from the mean ratings. This produced a substantial amount of variance in the ratings of each word, which indicates that individual valence impressions can vary considerably, despite high correspondence of mean impressions that are averaged over groups of subjects. For instance, the word snake received every possible rating from very unpleasant $(-3)$ to pleasant $(+2)$, though its mean rating was similar to the mean rating obtained in the pretest $(-0.3$ vs. -0.8$)$. Thus, it seemed implausible to use a normative classification that would locate this word in the category of slightly unpleasant words for all subjects. For the individual classification, each subject's ranking of his or her valence ratings was used: the six words that received the highest ratings were classified as strongly pleasant, the next six words as slightly pleasant, and so on. The mean ratings of the four word categories given by happy and sad subjects are presented in Figure 2 in the same way as the predictions of our model were presented in Figure 1.

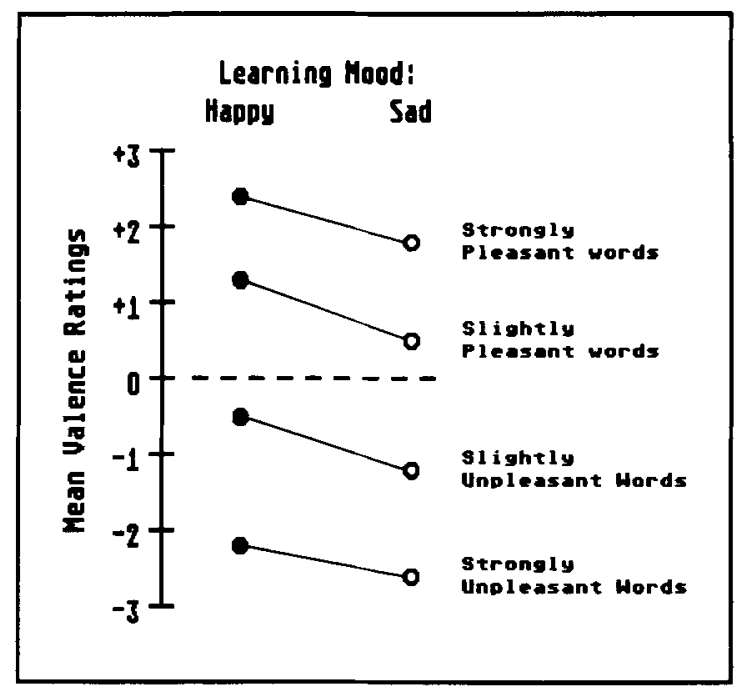

Figure 2. Mean valence ratings of the four word categories given by happy and sad subjects in Experiment 1. 
As Figure 2 shows, all four categories of words were rated as more pleasant by happy subjects than by sad subjects. The difference between both mood groups is statistically significant in every category [strongly pleasant, 2.4 vs. 1.8 ; slightly pleasant, 1.3 vs. 0.5 ; slightly unpleasant, -0.5 vs. -1.2 ; and strongly unpleasant, -2.2 vs. -2.6 ; all $F \mathrm{~s}(1,46)>5.33, p<.05]$. As expected, valence ratings of mood-incongruent words (pleasant words for sad subjects and unpleasant words for happy subjects) are biased toward the zero point of the rating scale, whereas ratings of mood-congruent words are biased away from it. Furthermore, a $2 \times 2 \times 2 \times 6$ factorial analysis of variance (ANOVA) using learning mood, word valence, valence intensity, and materials as factors revealed a significant interaction of mood and intensity $[F(1,46)=4.23$, $p<.05]$. The interaction indicates that, as predicted, the rating bias was more extreme for slightly toned words than for strongly toned ones. This is not surprising, because ratings of strongly toned words are subject to ceiling and floor effects.

Free recall. Each subject's recall data were analyzed by computing the number of words the particular subject recalled correctly from each category. These data were submitted to another $2 \times 2 \times 2$ factorial ANOVA using learning mood, word valence, and valence intensity as factors. The analysis revealed that the three-way interaction was significant $[F(1,46)=19.07, p<.01]$, indicating that the way the mood induction affected the recall of pleasant and unpleasant words depended on the valence intensity of the words. Therefore, separate analyses were computed for strongly and slightly toned words, as presented in Figure 3.

The mean percentage of strongly toned words recalled is shown in Figure 3a, broken down by learning mood and word valence. Figure $3 a$ shows mood-congruent learning of strongly toned words: a two-way (learning mood $x$ word valence) ANOVA revealed that the interaction was significant $[F(1,46)=5.5, p<.05]$. The main effects of learning mood and word valence were not significant. Planned comparisons showed that strongly unpleasant words were recalled more often if they had been learned in a sad mood rather than a happy mood [35\% vs. $27 \%, t(46)=2.16, p<.05]$. Accordingly, strongly pleasant words were recalled more often if they had been learned in a happy mood $[42 \%$ vs. $30 \%, t(46)=2.92$, $p<.01]$.

Figure $3 \mathrm{~b}$ shows the mean percentage of slightly toned words recalled, again broken down by learning mood and word valence. The two-way (learning $\operatorname{mood} x$ word valence) ANOVA revealed that the interaction was significant in this case as well $[F(1,46)=28.62, p<.01]$. Here, however, the interaction indicates mood-incongruent learning: slightly unpleasant words were recalled more often if they had been learned in a happy mood rather than a sad $\operatorname{mood}[24 \%$ vs. $5 \%, t(46)=4.67, p<.01]$. Accordingly, slightly pleasant words were recalled more often if they had been learned in a sad mood $[40 \%$ vs. $19 \%$, $t(46)=4.11, p<.01]$. The only statistically reliable

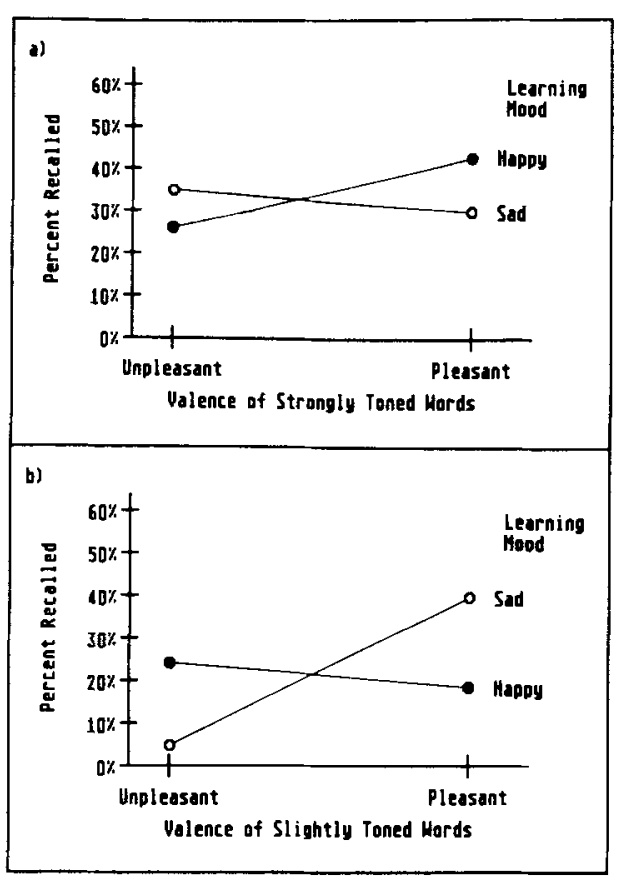

Figure 3. Mean percentage of words correctly recalled in Experiment 1 for (a) strongly toned words and (b) slightly toned words.

main effect was word valence $[F(1,46)=19.07, p<.01]$ : slightly pleasant words were recalled more often than slightly unpleasant words ( $30 \%$ vs. $15 \%$ ).

The results indicate that using the same experimental task, both mood-congruent and mood-incongruent learning can in fact be observed, depending on the intensity of the emotional valence of the materials. In the case of strongly toned words, the expected congruence effect was observed: congruence of learning mood and word valence (i.e., happy mood and pleasant words, sad mood and unpleasant words) led to better learning than did incongruence of mood and valence. As expected, the reverse was true for slightly toned words: incongruence of learning mood and word valence resulted in better learning than did congruence.

Our explanation of the incongruence effect, which is based on the ease of valence determinations, is supported by the finding that the expected rating bias was observed. Nevertheless, it remains unclear whether the rating bias affected the ease of valence determinations in the expected way (i.e., whether ratings of slightly mood-congruent words were facilitated and ratings of slightly moodincongruent words were rendered more difficult). This question was left unanswered by Experiment 1, but it can be answered by measuring the time subjects need to rate mood-congruent and mood-incongruent words. From our model, a straightforward prediction can be derived: If the valence of slightly mood-incongruent words is in fact more difficult to determine than the valence of slightly moodcongruent words, rating times of the first should be longer than rating times of the latter. In this case, it would seem 
reasonable to assume that subjects have to invest more cognitive effort in determining the emotional valence of slightly mood-incongruent words and would therefore learn them better. With regard to strongly toned words, we do not expect rating times to differ between moodcongruent and mood-incongruent words because the valence is easy to determine in both cases. These two word groups should differ only with regard to the amount of additional elaboration during the interval between the rating of a word and the presentation of the next word. These predictions were tested in Experiment 2.

\section{EXPERIMENT 2}

Experiment 2 was designed with two major goals in mind: First, we intended to replicate the finding of moodincongruent learning of slightly toned words. This seemed necessary because mood-incongruent learning was rarely reported before and mood-incongruent learning of slightly toned words in particular was never reported before. Therefore, our theorizing about it should be based on safer evidence than the first experiment can provide alone. To make our case even stronger, we used a new and longer list of words, as well as a shorter retention interval, in order to replicate the results of Experiment 1 under considerably different circumstances. Second, we wanted to test the rating-time prediction derived from the assumptions of our model about the cognitive processing of slightly toned words. The basic design and procedure of Experiment 2 were identical to those of Experiment 1.

\section{Method}

Design. The design of Experiment 2 was identical to that of Experiment 1, with the exception that an additional dependent variable was measured (i.e., the time needed to rate each word).

Subjects. Sixty undergraduates of the Philipps-University Marburg participated as subjects in the experiment. They were paid for their participation. Twelve subjects had to be excluded from the analyses because they indicated an insufficient effect of the mood induction. As a consequence, the two mood induction groups comprised 24 subjects each. The subjects were randomly assigned to the two mood inductions.

Materials. In a pretest, 220 two-syllable German nouns, verbs, and adjectives were rated for their emotional valence by 33 subjects in neutral mood. From this list, $\mathbf{4 0}$ words were selected for the experiment (i.e., 10 words in each of the four categories). The words were selected according to the following criteria: strongly toned words had a mean rating below -2 or above +2 , and slightly toned words had a mean rating between -1.6 and -0.7 or between +0.7 and +1.6 . Furthermore, only words with ratings as homogeneous as possible were selected (i.e., words whose ratings had a standard deviation less than 1.6). Thus, we hoped to minimize individual deviations from the mean valence ratings. English translations of the German words are presented in Table 1, ordered by word categories and mean ratings. Another six words were used as practice words. None of the $\mathbf{4 6}$ words appeared in the instructions or in the mood inductions. As one can see by inspection of Table 1 , only 3 of the $\mathbf{4 0}$ experimental words had already been used in Experiment 1.

Procedure. The subjects were tested individually in a single session that lasted about $1 \mathrm{~h}$. First, the subjects rated their mood. This
Table 1

Experimental Words Used in Experiment 2 Ordered by Word Category and Mean Rating

\begin{tabular}{|c|c|c|c|c|}
\hline \multirow[b]{2}{*}{ Mean Rating } & \multicolumn{4}{|c|}{ Word Category } \\
\hline & $\begin{array}{c}\text { Strongly } \\
\text { Unpleasant }\end{array}$ & $\begin{array}{c}\text { Slightly } \\
\text { Unpleasant }\end{array}$ & & \\
\hline Most Unpleasant & $\begin{array}{l}\text { stingy } \\
\text { lonely } \\
\text { bomb } \\
\text { accident } \\
\text { ulcer } \\
\text { to hunger } \\
\text { slave } \\
\text { to torment } \\
\text { pain } \\
\text { to kill }\end{array}$ & $\begin{array}{l}\text { dirty } \\
\text { to stumble } \\
\text { chasm } \\
\text { to age } \\
\text { beggar } \\
\text { to hinder } \\
\text { wetness } \\
\text { wrecked } \\
\text { stubborn } \\
\text { labile }\end{array}$ & $\begin{array}{l}\text { to paint } \\
\text { avenue } \\
\text { jubilant } \\
\text { bird } \\
\text { to thank } \\
\text { sky } \\
\text { capable } \\
\text { poem } \\
\text { quiet } \\
\text { competent }\end{array}$ & $\begin{array}{l}\text { to love } \\
\text { to kiss } \\
\text { to laugh } \\
\text { enjoyment } \\
\text { sunny } \\
\text { friendship } \\
\text { peace } \\
\text { meadow } \\
\text { beauty } \\
\text { to play }\end{array}$ \\
\hline
\end{tabular}

was done by rating the same three statements about their mood as in Experiment 1. The statements were presented one by one on a computer screen, together with a 7 -point rating scale ranging from not true at all to perfectly true. These points corresponded to seven buttons on a separate response panel that rested comfortably on the subject's lap. The subjects gave their ratings by pressing one of the seven buttons. Next, the mood induction was administered in exactly the same way as in Experiment 1. Directly following the mood induction, the subjects rated the emotional valence of all 46 words. Each word was presented on the computer screen, together with a rating scale ranging from -3 to +3 .

The rating scale was the same as in Experiment 1. Again, the seven points of the rating scale corresponded to the seven buttons on the response panel. The subjects rated the valence of each word by pressing one of the buttons. Each word was presented for exactly $10 \mathrm{sec}$, regardless of whether a subject gave his or her rating before this time. This was necessary to avoid confounding of rating time and exposure duration. The value and time of each rating were recorded automatically. If the subject failed to rate a word during the 10-sec interval, this was considered a missing value and the next word appeared on the screen. Fortunately, this rarely happened. Due to the exposure duration of $10 \mathrm{sec}$, each subject could rate all 46 words in about $8 \mathrm{~min}$. The presentation order of the 40 experimental words was systematically varied to control for order effects.

Immediately following the rating task, the subjects rated their mood for a second time, again by means of the three mood statements. In addition, they were questioned by the experimenter about the strength and duration of the mood induction. Next, all subjects were put back into a neutral mood by use of the second relaxation instruction already used in Experiment 1. Following this, each subject participated in a distractor task for $15 \mathrm{~min}$. The task consisted of pronouncing numbers presented on a computer screen as quickly as possible. This task was intended to rule out effects of short-term memory without interfering with the semantic content of the experimental words. After the distractor task, the subjects rated their mood for a third time by means of the three mood statements. The triple mood rating together with the experimenter's questioning served as a manipulation check for the mood induction. Furthermore, an inspection of the last mood ratings ensured that all subjects were in a comparable neutral mood before the recall test. This test was administered directly after the third mood rating. It was a surprise free-recall test, as in Experiment 1, except that the subjects wrote the words on a sheet of paper. None of the subjects had expected this test. At the end of the session, the experimenter questioned the subjects about strategies they might have used to maintain the induced mood. Especially, they were asked whether they 
had intentionally focused on mood-congruent words, but no subject affirmed this question.

\section{Results and Discussion}

Classification of words into categories. Despite our attempts to minimize the variance of valence ratings, several subjects' ratings differed considerably from the mean ratings given in the pretest. As in Experiment 1, a normative classification according to the mean ratings of the pretest would have produced many misclassifications leading to an undesirable increase of error variance in the data. Thus, we decided to use the individual classification described above. Fortunately, this did not result in a confounding of learning mood and materials due to item-selection effects because the individual variations in the happy subjects' group matched those in the sad subjects' group almost perfectly. When all words were ordered by their mean valence rating, the happy subjects' rank order was almost identical to the sad subjects' rank order $(R=.95, p<.01)$. What was even more important, the classification of words was the same for both groups. Therefore, the following comparisons of word categories are based on categories that contain the same words in both mood groups. Moreover, both groups' rank orders agreed very well with the order determined by the pretest and shown in Table 1 (sad mood, $R=.90$, $p<.01$; happy mood, $R=.94, p<.01$ ).

Valence ratings. The mean ratings of the four word categories given by happy and sad subjects are presented in Figure 4 for comparison with the predictions of our model shown in Figure 1. The valence ratings were submitted to a $2 \times 2 \times 2 \times 10$ factorial ANOVA, including learning mood, word valence, valence intensity, and materials as factors. The analysis yielded a significant main effect of learning mood $[F(1,46)=44.73$, $p<.01]$, which is due to the fact that happy subjects gave

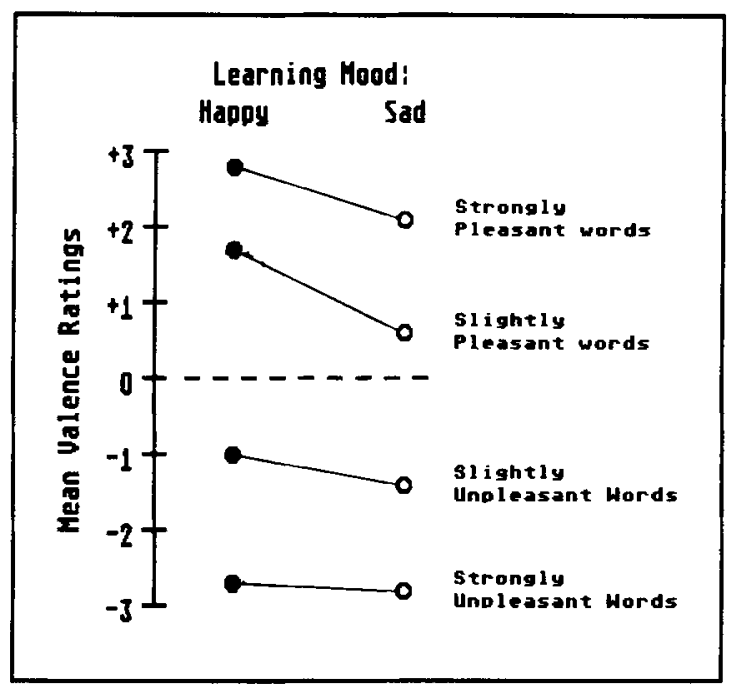

Figure 4. Mean valence ratings of the four word categories given by happy and sad subjects in Experiment 2. more positive ratings than did sad subjects (0.21 vs. -0.37 ). Moreover, a significant interaction of learning mood and valence intensity $[F(1,46)=24.79, p<.01]$ indicated that the rating bias caused by the induced mood was more extreme for slightly toned words than for strongly toned ones (a shift of 0.77 vs. 0.38). Separate analyses revealed that the ratings of happy and sad subjects did not differ significantly for strongly unpleasant words $[-2.7$ vs. $-2.8 ; F(1,46)<1]$, but for the remaining three categories [strongly pleasant, $2.8 \mathrm{vs.} 2.1$; slightly pleasant, 1.7 vs. 0.6 ; slightly unpleasant, -1.0 vs. -1.4 ; all $F \mathrm{~s}(1,46)>7.5, p<.01]$. To summarize, these results are in perfect accordance with the results of Experiment 1: The expected rating bias occurred, it was more extreme for slightly toned words, and it shifted mood-incongruent words toward the zero point of the rating scale, whereas mood-congruent words were shifted away from it.

Free recall. The recall data were analyzed in the same way as in Experiment 1. For each subject, the number of words correctly recalled from each word category was computed. These data were analyzed by a $2 \times 2 \times 2$ factorial ANOVA using learning mood, word valence, and valence intensity as factors. Again, the analysis revealed that the three-way interaction was significant $[F(1,46)=$ $31.57, p<.01]$, indicating that the way the mood induction affected the recall of pleasant and unpleasant words depended on the valence intensity of the words. Therefore, separate analyses were computed for strongly and slightly toned words as presented in Figure 5.

Figure 5a shows the mean percentage of strongly toned words recalled, broken down by learning mood and word valence. A two-way (learning mood $x$ word valence) ANOVA revealed that the interaction was significant $[F(1,46)=28.26, p<.01]$. The main effect of learning mood was not significant $[F(1,46)<1]$, whereas word valence was $[F(1,46)=17.45, p<.01]$, indicating that recall of strongly pleasant words was better than recall of strongly unpleasant words. Planned comparisons showed that the significant interaction was due to moodcongruent learning: strongly unpleasant words tended to be recalled more often if they had been learned in a sad mood rather than a happy mood $[38 \%$ vs. $31 \% ; t(46)=$ $1.56, p<.13]$. Accordingly, pleasant words were recalled more often if they had been learned in a happy $\operatorname{mood}[52 \%$ vs. $36 \% ; t(46)=3.47, p<.01]$.

Figure $5 \mathrm{~b}$ shows the mean percentage of slightly toned words recalled, again broken down by learning mood and word valence. Again, the two-way (learning mood $x$ word valence) ANOVA yielded a significant interaction of mood and valence $[F(1,46)=11.97, p<.01]$. However, in this case, the interaction indicates mood-incongruent learning: slightly unpleasant words were recalled more often if they had been learned in a happy mood rather than a sad mood [ $30 \%$ vs. $20 \% ; t(46)=2.63, p<.02]$. Accordingly, slightly pleasant words tended to be recalled more often if they had been learned in a sad mood [32\% vs. $25 ; t(46)=1.61, p<.12]$. The main effect of learn- 


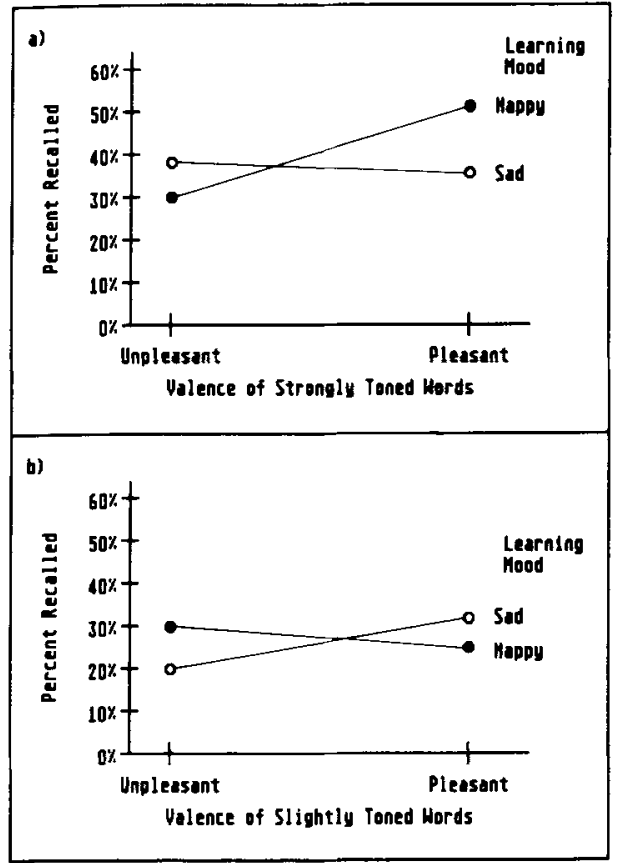

Figure 5. Mean percentage of words correctly recalled in Experiment 2 for (a) strongly toned words and (b) slightly toned words.

ing mood was not significant $[F(1,46)<1]$, and there was a tendency for slightly pleasant words to be recalled more often than slightly unpleasant words $[F(1,46)=$ $2.84, p<.10$ ]. Despite the fact that not all of the relevant pairwise comparisons are statistically significant, the recall data show the expected interactions of learning mood and valence intensity: mood-congruent learning of strongly toned words and mood-incongruent learning of slightly toned words.

Rating times. For each subject, the mean rating time of each word category was computed. These rating times were submitted to a $2 \times 2 \times 2$ factorial ANOVA, including learning mood, word valence, and valence intensity as factors. The analysis revealed a significant interaction of mood, valence, and intensity $[F(1,46)=12.4$, $p<.01$ ], indicating that the way the mood induction affected the rating times of pleasant and unpleasant words depended on the valence intensity of the words. Therefore, separate analyses were computed for strongly and slightly toned words as shown in Figure 6.

Figure $6 \mathrm{a}$ shows the mean rating times of strongly toned words, broken down by learning mood and word valence. A $2 \times 2$ factorial ANOVA, including mood and valence as factors, yielded no significant effects. This agrees with the prediction that the slight rating bias of strongly toned words should not affect the ease of rating them: words with an unequivocal emotional valence remain easy to rate even if the mood induction shifts the ratings a little to the neutral point.

The mean rating times of slightly toned words are shown in Figure $6 \mathrm{~b}$, again broken down by learning mood and valence intensity. The two-way ANOVA of these data revealed only one significant effect, namely, the two-way interaction $[F(1,46)=27.31, p<.01]$. This is due to the expected effect of mood on rating times: congruent combinations of mood and valence resulted in faster ratings than incongruent combinations. Slightly pleasant words were rated more quickly by happy subjects than by sad subjects $[3,028 \mathrm{msec}$ vs. $3,960 \mathrm{msec} ; t(46)=3.4$, $p<.01]$. For slightly unpleasant words, the difference was smaller and statistically not significant $[3,568 \mathrm{msec}$ vs. $3,717 \mathrm{msec} ; t(46)=.44$, n.s.]. Apart from this, the rating times are in perfect accordance with our expectations.

To summarize the results of Experiment 2, valence ratings, recall data, and rating times indicate that the rating bias did not only occur but that it also had the expected effect on the cognitive processing of the words. The valence of slightly mood-incongruent words was shifted toward the neutral point, rendering the valence determination of these words slower and more difficult. On the other hand, the valence of slightly mood-congruent words was shifted away from the neutral point, making their valence determination easier and faster. As a consequence, the subjects processed slightly mood-incongruent words more intensively than they processed slightly moodcongruent ones, and they recalled them better later on. This is true despite constant exposure duration of all words, which supports the hypothesis that the effect is due to differences in intensity of processing. With regard to strongly toned words, the ease of determining their valence was not affected by the rating bias. Strongly toned words produced the well-known effect of mood-congruent learning (i.e., they were recalled better if they had been

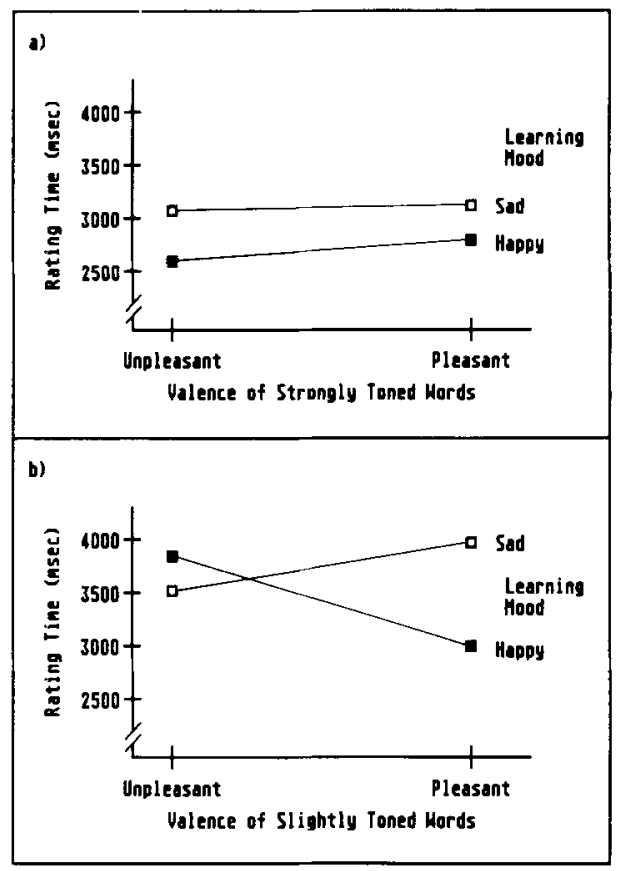

Figure 6. Mean valence rating times in Experiment 2 for (a) strongly toned words and (b) slightly toned words. 
learned in a congruent mood). Considering valence ratings and recall data, the results of Experiment 2 constitute a replication of the results of Experiment 1, even though the set of materials, the retention interval, and several experimental details differed. In addition, rating times observed in Experiment 2 provide evidence for the explanation we offered for the mood-incongruent learning of slightly toned words.

\section{GENERAL DISCUSSION}

The results of both experiments show that moodincongruent learning is more than a "neglected possibility" (Fiedler et al., 1986) that is found only rarely and by chance. It can be provoked, experimentally investigated, and theoretically explained using experimental paradigms such as the one reported here. We observed mood-incongruent learning of incidentally learned words that were only slightly emotionally toned, because slightly mood-incongruent words were processed more intensively during the learning phase than were slightly moodcongruent words. At the same time, we observed moodcongruent learning of strongly toned words, presumably because strongly mood-congruent words received more mood-maintaining elaborations than did strongly moodincongruent words. Both effects were observed using the same rating task and identical mood inductions. Whether one effect or the other occurred depended on the nature of the experimental material (i.e., the intensity of its emotional valence).

The results show that mood does not produce moodcongruent learning directly and automatically, as proposed by a simple network model of emotion. Rather, it influences the cognitive processing of the learning material in a more complex way, so that mood-congruent, as well as mood-incongruent, learning can occur, depending on the specific interaction of mood, experimental task, and materials. The results of this interaction are predicted by a model that extends the process assumptions of the original network model (Bower, 1981; Bower \& Cohen, 1982). The extended model separates the effects of an induced mood on two different processes that occur during the learning task. According to our model, differences in the ease of valence determination lead to moodincongruent learning of slightly toned words, whereas differences in the amount of additional elaboration after the completion of the valence determination lead to moodcongruent learning of strongly toned words. The adequacy of the model for the explanation of mood-incongruent learning is demonstrated further by rating times observed in Experiment 2. They show that the rating bias indeed renders the valence determination of slightly incongruent words more time-consuming and therefore presumably more difficult than the valence determination of slightly congruent words.

Different from our two-component processing model, the original model proposed by Bower (1981) and Bower and Cohen (1982) includes explanations for mood- congruent learning but does not deal with valence determination. We believe that the simpler model is useful and sufficient as long as the experimental materials have a strong emotional tone and only mood-congruent learning has to be explained. Unfortunately, this is often but not always the case. For one thing, the valence intensity of the materials used in studies of mood-congruent learning remains unclear because relevant data are usually not reported. Moreover, including our study, there are at least three reported instances of mood-incongruent learning (Clark et al., 1983; Fiedler et al., 1986).

The results reported here highlight the importance of properties of experimental materials. Depending on properties such as valence intensity, completely different results can be observed. Unfortunately, in mood and memory research, the properties of the materials being used often do not receive the attention they deserve. This is true for research on mood-dependent retrieval, where the valence of the materials is supposed to be neutral or of no special importance (see Blaney, 1986). Our results indicate that a closer look at the features of the materials might be helpful for research on mood-congruent learning as well. It might explain cases of unsuccessful attempts to replicate mood-congruent learning (e.g., Kelley, 1982; Mecklenbräuker \& Hager, 1984). The materials used in studies of mood congruence usually consist of stimuli with a variable degree of valence intensity. Therefore, opposite effects with slightly and strongly toned stimuli might cancel each other out. For example, the clear pattern of results of our experiments would have been completely obscured if we had failed to distinguish between slightly and strongly toned words. Unfortunately, this distinction has never been made in research on mood-congruent learning as far as we know. The valence of the materials was simply classified as negative, neutral, or positive, ignoring possible transitions from one category to another.

Another important result also refers to the classification of the emotional valence of the materials. In both experiments, many individual classifications differed considerably from the normative classifications of the pretests, despite good agreement when ratings were averaged over subjects. The differences were large enough to obscure the effects found in both experiments if we had chosen a normative classification. This indicates that it might be unfounded to presume that the affective tone being considered is preexisting and normative, as it is usually done (Blaney, 1986). Instead, we have to expect considerable variance in the individual impressions of the valence of the materials. It seems useful to deal with this variance in order to reduce error variance that might lead to inconclusive results. One way to achieve this is by means of an individual classification, if this does not lead to confounding the independent variables with the materials used. Unfortunately, this can be tested only after the experiment, and it may take large samples to meet this requirement.

The assumption that mood affects cognitive processes in a complex way, which in turn produces mood-dependent 
phenomena, is quite consistent with the results of Perrig and Perrig (1988; Perrig \& Perrig-Chiello, 1985). They argued for the importance of subjects' knowledge about mood states and the appropriate behavior after showing that mood-congruent learning can also occur if subjects are instructed to behave as if they were happy or depressed. An advantage of the paradigm reported here is that the results are not as prone to an experimenter-demand explanation as are the results of Perrig and Perrig. It is quite implausible that subjects could have guessed the different hypotheses for slightly and strongly toned words and produced the appropriate rating times accordingly.

Although the proposed model could predict the observed results quite well, many questions remain unanswered. Further research should investigate the applicability of the model to other experimental paradigms. Exactly when will mood-incongruent learning, as opposed to mood-congruent learning, be observed? We suspect that better learning of slightly mood-incongruent stimuli might appear whenever subjects are dealing with the emotional valence of the materials. Therefore, a promising line of research would use the same set of materials, once for a task comparable to the valence rating used here and once for a task that presumably keeps subjects from considering the valence of the words (e.g., counting their letters). Another question refers to the theoretical explanation of mood-congruent learning. In the original network model as well as in our extended model, at least two different explanations are possible. Further research should determine whether stimulusinduced differences in mood intensity, subjects' moodmaintaining strategies, or both lead to mood congruency. Regarding the current state of affairs, mood-congruent learning seems like an often observed, but insufficiently explained, phenomenon to us. We do believe, however, that the experiments reported here contribute to the understanding of mood-incongruent learning.

\section{REFERENCES}

BASCheK, I., Bredenkamp, J., OEhrLe, B., \& WiPPICH, W. (1977). Bestimmung der Bildhaftigkeit, Konkretheit und der Bedeutungshaltigkeit von 800 Substantiven. Zeitschrift für experimentelle und angewandre Psychologie, 24, 353-396.

Blaney, P. H. (1986). Affect and memory: A review. Psychological Bulletin, 99, 229-246.

Bower, G. H. (1981). Mood and memory. American Psychologist, 36. 129-148.

Bower, G. H. (1987). Commentary on mood and memory. Behavior Research \& Therapy, 25, 443-455.

Bower, G. H. . COHEN, P. R. (1982). Emotional influences in memory and thinking: Data and theory. In M. S. Clark \& S. T. Fiske (Eds.), Affect and cognition (pp. 291-331). Hillsdale, NJ: Erlbaum.

Bower, G. H., Gilligan, S. G., * Monteiro, K. P. (1981). Selectivity of learning caused by affective states. Joumal of Experimental Psychology: General, 110, 451-473.
Clark. D. M. . Teasdale, J. D. (1982). Diurnal variation in clinical depression and accessibility of memories of positive and negative experiences. Journal of Abnormal Psychology. 91, 87-95.

Clark, D. M., Teasdale, J. D., Broadbent, D. E., Martin, M. (1983). Effect of mood on lexical decisions. Bulletin of the Psychonomic Society, 21, 175-178.

Derry, P., KuIPER, N. (1981). Schematic processing and selfreference in clinical depression. Joumal of Abnomal Psychology. 90. 286-297.

Eich, E., Metcalfe, J. (1989). Mood dependent memory for internal versus external events. Joumal of Experimental Psychology: Leaming. Memory, \& Cognition, 15, 443-455

Fiedler, K., PAmpe, H., Scherf, U. (1986). Mood and memory for tightly organized social information. European Joumal of Social Psychology, 16, 149-164.

Fiedler, K., Ströhm, W. (1986). What kind of mood influences what kind of memory: The role of arousal and information structure. Memory \& Cognition, 14, 181-188.

Forgas, J. P., Bower, G. H., Krantz, S. E. (1984). The influence of mood on perception of social interactions. Journal of Experimental Social Psychology, 20, 497-513.

GUENTHER, R. K. (1988). Mood and memory. In G. M. Davies \& D. M. Thomson (Eds.), Memory in context: Context in memory (pp. 57-80). New York: Wiley.

Isen, A. M., Shalker, T. E., Clark, M., a Karp, L. (1978). Affect, accessibility of material in memory, and behavior: A cognitive loop? Journal of Personality \& Social Psychology, 36, 1-12.

Kavanagh, D. J., Bower, G. H. (1985). Mood and self-efficacy: Impact of joy and sadness on perceived capabilities. Cognirive Therapy \& Research, 9, 507-525.

KELLEY, C. M. (1982). Some effects of moad on attention and memory. Unpublished doctoral dissertation, Stanford University, Stanford, CA.

LAMBERT, D. (1985). Experimenselle Untersuchung zur stimmungsabhangigen Wahmehmung der sozialen Unterstarzung. Unpublishod thesis, University of Marburg. Marburg, Germany.

Mecklengräuker, S., Hager, W. (1984). Effects of mood on memory: Experimental tests of a mood-state-dependent hypothesis and of a mood-congruity hypothesis. Psychological Research, 46, 355-376.

Perrig, W. J., Perrug, P. (1988). Mood and memory: Moodcongruity effects in absence of mood. Memory \& Cognition. 16. 102-109.

Perrig. W. J., \& Perrug-Chiello, P. (1985). Selektives Lemen bei induzierten Stimmungszuständen: Resultat des Stimmungszustandes oder bloss der Aufgabenstellung? Schweizerische Zeitschriff fur Psychologie, 44, 17-30.

Roth, D., Reнм, L. P. (1980). Relationships among self-monitoring processes, memory, and depression. Cognitive Therapy \& Research. 4, 149-157.

SNyder, M., \& Wite, P. (1982). Moods and memories: Elation, depression, and the remembering of the events of one's life. Joumal of Personaliry, 50, 142-167.

Teasdale, J. D., Russell, M. L. (1983). Differential effects of induced mood on the recall of positive, negative, and neutral words. British Journal of Clinical Psychology, 22, 163-171.

VELTEN, E. (1968). A laboratory task for induction of mood states. Behavior Research \& Therapy, 6, 473-482.

Weingartner, H., Miller, H., MurPhy, D. L. (1977). Mood-statedependent retrieval of verbal associations. Journal of Abnormal Psychology, 86, 276-284.

WIPPICH, W., BREDENKAMP, J. (1979). Bildhaftigkeit und Lernen. Darmstadt, Germany: Steinkopff.

(Manuscript received March 20, 1991; revision accepted for publication July 1, 1991.) 